\title{
Macroscopic Behaviors of Dioxins in the Iron Ore Sintering Plants
}

\author{
Eiki KASAI, ${ }^{1)}$ Teruhiko AONO, Yukio TOMITA, Makoto TAKASAKI, Norihisa SHIRAISHI and Shinji KITANO \\ The Collaborative Research Project for Suppression of Dioxins Emissions from the Sintering Process (SDD Project), Japan. \\ 1) Institute for Advanced Materials Processing, Tohoku University, 1-1, Katahira, Sendai 980 Japan.
}

(Received on August 31, 2000; accepted in final form on October 23, 2000)

\begin{abstract}
The emissions of dioxins to the environmental air from iron ore sintering plants become to be regulated by the new Japanese law against dioxins. The emissions from Japanese sintering plants have been already fairly low levels by large efforts made so far for their reduction. However, substantial and systematic countermeasures are not yet developed and, further, detailed information has not been available on the formation/decomposition of dioxins in the sintering plant.

In the present investigation, two different plants were chosen and samplings were made for gaseous, liquid and solid materials at various positions of the processes. Concentrations of dioxins and other compounds of the samples were analyzed. Understanding of the characteristics of the dioxins formation in the sintering process has been attempted on the basis of the analytical results. Macroscopic behavior of dioxins in the sintering and waste gas treatment processes is discussed. Further, the results of the plant test obtained with and without use of recycling materials are reported.
\end{abstract}

KEY WORDS: sintering process of iron ores; dioxins; PCDD/Fs; co-PCBs; plant test; mass balance; recycle dust; fingerprint; waste gas treatment process.

\section{Introduction}

The Environment Agency of Japan promulgated the "law concerning special measures against dioxins" on July 16, 1999 and it was enforced on January 15, 2000. In the law, TDI (Tolerable Daily Intake) for dioxins is formulated as "it shall not exceed 4 picograms (in TEQ (Toxicity Equivalent Quantity) per kilogram of body mass and shall be set forth by Cabinet Order". Co-PCBs (co-planar polychlorinated biphenyls) are enumerated in "dioxins" as well as PCDDs (polychlorinated dibenzo- $p$-dioxins) and PCDFs (polychlorinated dibenzofurans). Based on this, the environmental quality standards have been provided for the conditions relating to air, water and soil pollutions/contaminations. These values have been designated in the related government ordinance as $0.6 \mathrm{pg}$-TEQ $/ \mathrm{Nm}^{3}$ for air, $1 \mathrm{pg}$-TEQ/L for water and $1000 \mathrm{pg}-\mathrm{TEQ} / \mathrm{g}$-dry for soil. Further, it describes that the emission standards shall be set for newly "specified facilities" rather than waste incinerators and electric furnaces used for steelmaking. Thus, the sintering plant of iron ores have been classified as a "specified facility" with respect to the air pollution and its waste gas becomes to be controlled under its emission standard.

In 1997, a collaborative research project was formed by the researchers and engineers of Japanese integrated steel makers and universities. The project is supported by the Steel Industry Foundation for the Advancement of Environmental Protection Technology. The objective of the project is to clarify the behaviors of dioxins and relating substances in the sintering process and to search for new technological principles for suppression of the emissions rather than waste gas treatments. It has carried out reviews of previous literatures and data, several plant measurements and tests, experiments using process simulators (sinter-pots) and fundamental researches.

The present paper deals with the results of the measurements and analyses on the sinter plants. Characteristics of behaviors and flows of dioxins in the sintering bed, windboxes (WBs) and the gas treatment processes are discussed as well as those of other gas species. Further, the results of the plant test obtained with and without use of recycling materials are reported.

\section{Inventory of Dioxins Sources in Japan and its Future Trends}

Table 1 shows major sources of dioxins and their amounts in Japan. Remarkably large reductions are seen in the emissions from both municipal and industrial waste incinerators within two years from 1997 to 1999. However, further reduction of the emissions is strongly required for the waste incinerators. On the other hand, other "specified facilities" with respect to the air emissions, such as electric furnaces for steelmaking, zinc recovery processes from EAF (Electric arc furnace) dust and aluminum recycle processes, are recycle processes of base metals. The former two processes give significant reduction in the emissions. Remarkable reduction was also achieved in the sintering 
Table 1. Inventory for major dioxins sources of environmental releases to air in Japan: 1997, 1998 and 1999 (including co-PCBs, unit in g-TEQ/year).

\begin{tabular}{lccc}
\hline Sources & 1997 & 1998 & 1999 \\
\hline Domestic waste incinerators & 5000 & 1550 & 1350 \\
Industrial waste incinerators & 1500 & 1100 & 690 \\
Small waste incinerators & $340 \sim 591$ & $340 \sim 591$ & $279 \sim 481$ \\
Electric arc furnace (steel) & 228 & 139.9 & 141.5 \\
Iron ore sintering & 135 & 113.8 & 101.3 \\
Secondary zinc production & 42.3 & 20.4 & 18.4 \\
Secondary aluminum production & 21.3 & 19.4 & 13.6 \\
Rolled copper production & 3.16 & 3.16 & 1.16 \\
Paper manufacturing & 5.3 & 5.3 & 5.3 \\
Copper smelters & 4.91 & 4.91 & 0.46 \\
Crematories & $2.1 \sim 4.6$ & $2.2 \sim 4.8$ & $2.2 \sim 4.8$ \\
Steam power plant & 1.63 & 1.55 & 1.64 \\
Electric wire \& cable production & 2.21 & 2.21 & 1.21 \\
Cement kilns & 2.47 & 2.47 & 2.32 \\
Aluminum rolling & 1.61 & 1.61 & 1.46 \\
Smoking & $0.1 \sim 0.2$ & $0.1 \sim 0.2$ & $0.1 \sim 0.2$ \\
Exhaust gas from automobiles & 1.12 & 1.12 & 1.12 \\
Others (including release to water) & 7.3 & 6.8 & 4.8 \\
\hline Total & & & \\
\hline
\end{tabular}

process of iron ores as shown in Table 1.

The enforced regulations for the iron ore sintering processes are $0.1 \mathrm{ng}-\mathrm{TEQ} / \mathrm{Nm}^{3}$ for newly constructed plants and $1 \mathrm{ng}-\mathrm{TEQ} / \mathrm{Nm}^{3}$ for currently operating plants on the basis of $\mathrm{O}_{2} 15 \%$ in flue gas. In fact, according to the measurements by own and the Environment Agency, the average dioxins concentration of the flue gas for the sintering plants in Japan is lower than $1 \mathrm{ng}-\mathrm{TEQ} / \mathrm{Nm}^{3}$. However, continuous efforts will be necessary to reduce dioxins emissions from the sintering process.

\section{Characteristics of the Dioxins Behavior in the Sinter Plant}

An official investigation for dioxin concentration of waste gas at the stack was carried out for the sinter plant in Germany. ${ }^{1)}$ The result showed that the average concentration in three measurements was $43 \mathrm{ng}-\mathrm{TEQ} / \mathrm{Nm}^{3}$. This was not lower value than those measured for municipal waste incinerators which had been already regarded as facilities needing a countermeasure against dioxins emissions. However, the necessary information has not been accumulated so far. The largest reason is that concentration of dioxins is extremely low, e.g., in the order of $\mathrm{ng} / \mathrm{Nm}^{3}$. This leads to insufficient accuracy and extremely higher cost for the analysis. The next reason is difficulty in sampling method. The Japanese Industrial Standard (JIS) K 0311 ${ }^{2}$ describes that the collected amounts of dioxins in the gas must be greater than 30 times of the detection limit. This usually leads to larger volume of sample gas and therefore longer sampling time. This means that the result of an unsteadystate process, such as a sinter pot test, will give only an average value of the fluctuated concentration. Further, reliable and sufficient information on dioxins has still not been always available even on the general properties and formation/decomposition mechanisms of dioxins and relating

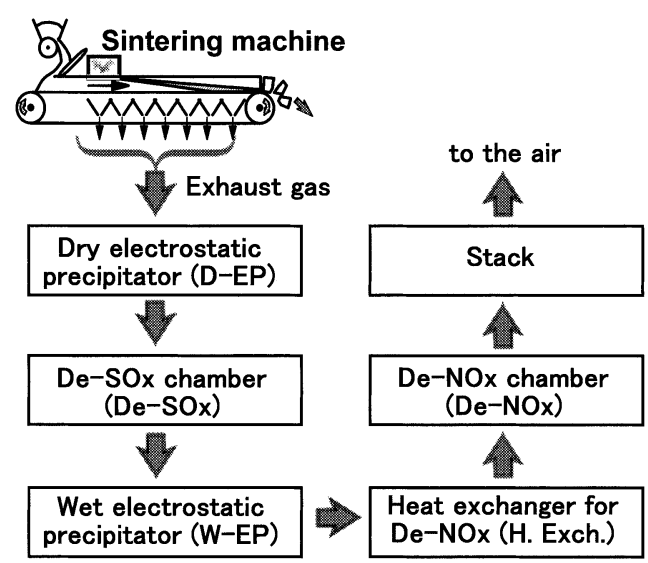

Fig. 1. Flow scheme of exhaust gas treatment processes in plant A.

compounds.

\subsection{Plant Measurements}

Considering the above problems, comprehensive measurements were conducted for two sinter plants in order to understand macroscopic behavior of dioxins. Samplings were made for gases in WBs, at the inlets and outlets of gas treatment equipments, raw materials, produced sinter, return fines, dusts, some waste water and so fourth. Methods of sampling and analysis of dioxins in gases are in accordance with the JIS procedures for stationary source emissions. ${ }^{2)}$ Analyzed dioxins were mainly tetra- through octachlorinated dibenzo- $p$-dioxins (4-8CDDs) and dibenzofurans (4-8CDFs) and partially co-PCBs. PCDDs and PCDFs will hereinafter be abbreviated "PCDD/Fs" to distinguish from co-PCBs. The term "dioxins" will be used when such distinction will not be necessary. Toxicity equivalent concentration of dioxins will be distinguished from an actual value by putting TEQ to the unit.

The first measurement was made for the plant $\mathrm{A}$ with a sintering machine possessing $210 \mathrm{~m}^{2}$ of effective sintering area and about $9600 \mathrm{Mg} / \mathrm{d}$ of production rate. Bed thickness and number of WBs are $660 \mathrm{~mm}$ and 15 , respectively. Outlet gas discharged through WBs is flowed to a dry electrostatic precipitator (D-EP), a wet desulfurization facility (De-SOx), a wet electrostatic precipitator (W-EP), a denitration facility (De-NOx), in this order, and exhausted from a stack. The flow scheme of exhaust gas from the sintering machine to the stack is illustrated in Fig. 1.

The second measurement was conducted for plant B having a D-EP. The effective sintering area is $330 \mathrm{~m}^{2}$ and production rate is about $10000 \mathrm{Mg} / \mathrm{d}$. Bed thickness and number of WBs are $670 \mathrm{~mm}$ and 21, respectively.

Major raw materials used at the measurements and production rates are listed in Table 2.

\subsection{Distribution of PCDD/Fs Concentration of Ex- haust Gas from Windboxes (WBs)}

Figure 2 shows changes in relative concentrations of PCDD/Fs along WBs comparing with those of other gas species and temperature. The abscissa in the figure is the relative position of windboxes, i.e., " 0 " is the first and " 1 " is the last windboxes. NOx shows a comparatively flat profile for both plants. These are fairly similar to the $\mathrm{CO}_{2}$ pro- 
Table 2. Major production parameters of plant A and B.

\begin{tabular}{llcc}
\hline Plant & & $\mathrm{A}$ & $\mathrm{B}$ \\
\hline Production & & $9,600 \mathrm{Mg} / \mathrm{d}$ & \multicolumn{1}{c}{$10,000 \mathrm{Mg} / \mathrm{d}$} \\
\hline \multirow{6}{*}{ Raw } & Iron ores & $8,770 \mathrm{Mg}$-wet/d & $7,660 \mathrm{Mg}$-wet/d \\
& Limestone & $560 \mathrm{Mg}$-wet/d & $1,090 \mathrm{Mg}$-wet/d \\
& Burnt lime & $120 \mathrm{Mg}$-wet/d & $170 \mathrm{Mg}$-wet/d \\
& Coke & $310 \mathrm{Mg}$-wet/d & $410 \mathrm{Mg}$-wet/d \\
materials & Returned sinter & $620 \mathrm{Mg}$-dry/d & $1,770 \mathrm{Mg}$-wet/d \\
& Ni-slag & $70 \mathrm{Mg}$-wet/d & - \\
& Dust & $400 \mathrm{Mg}$-wet/d & $390 \mathrm{Mg}$-wet/d \\
& LD slag & $400 \mathrm{Mg}$-wet/d & - \\
& Mill scale & $200 \mathrm{Mg}$-wet/d & $470 \mathrm{Mg}$-wet/d \\
& Serpentine & - & $310 \mathrm{Mg}$-wet/d \\
& Others & $408 \mathrm{Mg}$-wet/d & $1,300 \mathrm{Mg}$-wet/d \\
\hline
\end{tabular}

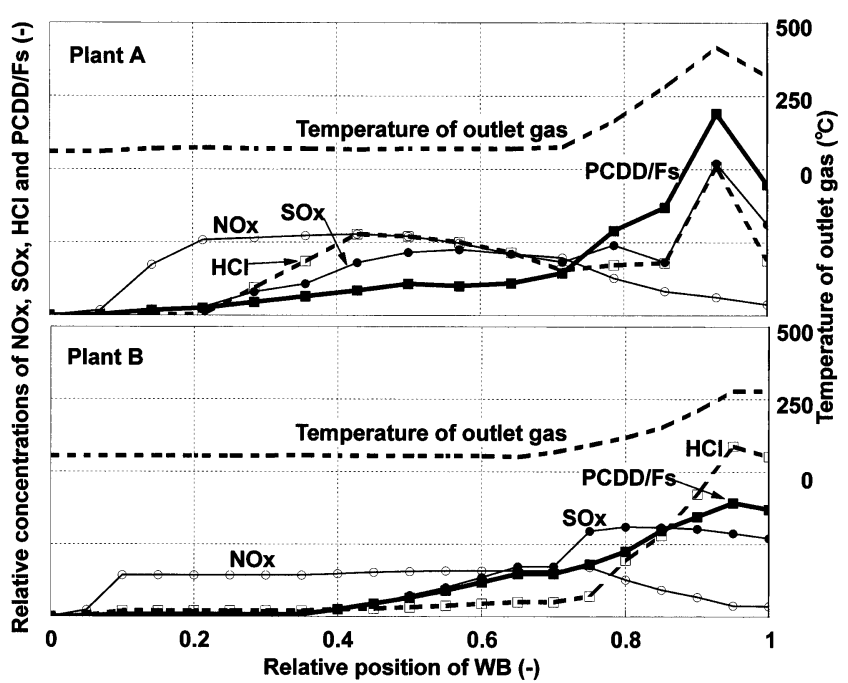

Fig. 2. Changes in exhaust gas temperatures and relative concentrations of $\mathrm{PCDD} / \mathrm{Fs}$ and other gases in windboxes with progressing of sintering.

files. In contrast, concentration of PCDD/Fs give a peak near the end of sintering which is reasonably similar to temperature profile. Such trend agrees fairly well with the measurements by Putz and Gudenau. ${ }^{3)}$ Concentration of SOx also increases in the later stage of sintering, but its peak appears slightly earlier than that of PCDD/Fs. The profiles of $\mathrm{HCl}$ concentration are also similar to those of $\mathrm{PCDD} / \mathrm{Fs}$.

The reason why SOx is discharged in the later stage of the sintering can be described simply as follows: SOx formed and transferred to the gas stream in combustion zone of sintering bed is trapped in the low temperature zone; the trapped SOx move again to gas stream due to increase in bed temperature; SOx accumulated by such a way is then discharged at the near end of the sintering. A similar mechanism may be act to the discharging processes of $\mathrm{HCl}$ and PCDD/Fs.

Figure 3 shows the relations between cumulative amount of discharged $\mathrm{CO}+\mathrm{CO}_{2}$, which is an indicator representing the progress of sintering, and those of other gas species. Change in the concentration ratio of PCDDs to PCDFs is also shown in the figure. It is clear for both plants that these gases are discharged in the later stage than $\mathrm{CO}+\mathrm{CO}_{2}$. The order of such trends is PCDD/Fs, SOx and then $\mathrm{HCl}$ for plant $\mathrm{A}$, but is $\mathrm{HCl}, \mathrm{PCDD} / \mathrm{Fs}$ and $\mathrm{SOx}$ for plant $\mathrm{B}$. It is not

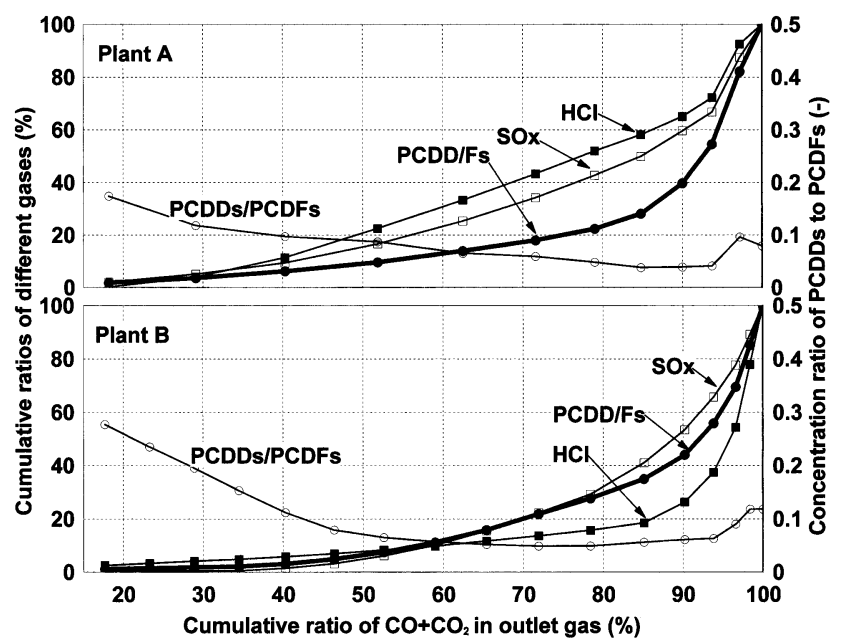

Fig. 3. Relation between cumulative ratios of $\mathrm{CO}+\mathrm{CO}_{2}$ and other gas species

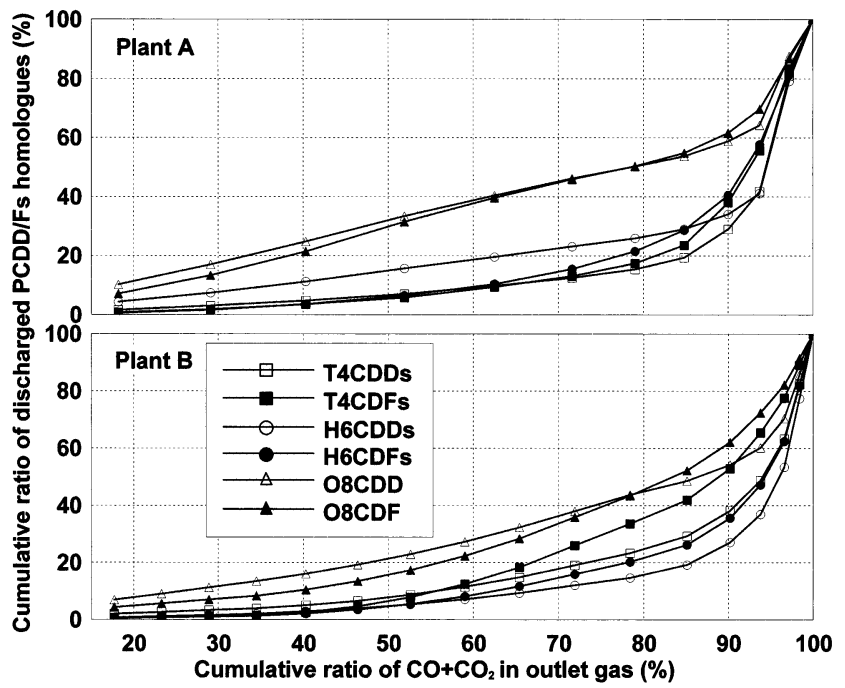

Fig. 4. Relation between cumulative ratios of discharged $\mathrm{CO}+\mathrm{CO}_{2}$ and PCDD/Fs homologues.

clear on the reason of the difference in discharging profiles of $\mathrm{HCl}$ between these plants. It may be possible to attribute to the differences of operational conditions, e.g., raw materials, production rate and so forth. It is necessary to further examine the effect of raw materials. Properties of recycle materials, especially EP dust, appear to be considerably different depending on the gas treatment processes and the pretreatment methods of the dust before use as raw materials for sintering.

The cumulative profiles of discharged PCDD/Fs homologues are shown in Fig. 4. The higher chlorinated homologues, i.e., $\mathrm{O} 8 \mathrm{CDD} / \mathrm{F}$, are discharged earlier than the lower chlorinated homologues, i.e., T4CDD/Fs. Such tendency is consistent for both plants and for almost all the homologues. However, the tendency is more significant for plant A than B. The reason of the difference is still unknown. Gas velocity through sintering bed, temperature profile of the sintering bed and/or concentration and combined forms of chlorines in raw materials may affect the above phenomena. It is notable that this phenomenon is conflict with the fact that the saturated vapor pressures of the dioxins homo- 


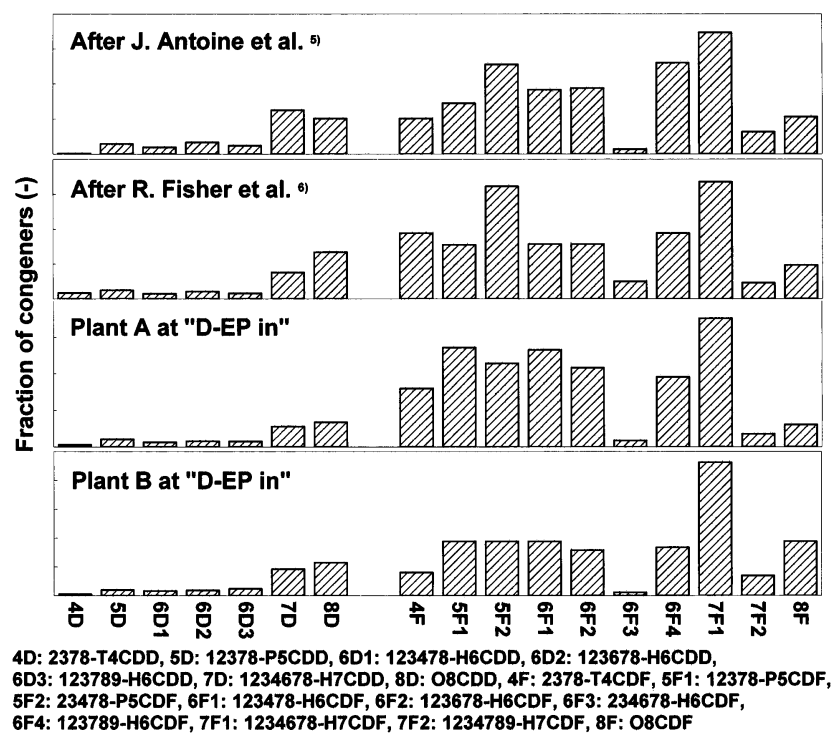

Fig. 5. Congener profiles of $\mathrm{PCDD} / \mathrm{Fs}$ observed in the exhaust gas of the sintering process.

logues generally decrease with an increase in the number of chlorination. ${ }^{4)}$

\subsection{Fingerprint of PCDD/Fs Congeners}

When dioxins formed from specific precursor(s), specific congener(s) of dioxins significantly form reflecting the structure of the precursor(s). Such formations were observed typically at the production of agricultural chemicals and the bleaching process of paper production in the past time. In these cases, an emission source can be sometimes specified from the congener profile detected in the atmospheric air, water or soil. Combustion processes like waste incinerators mostly give similar congener profiles, so-called incineration pattern, which does not show the significant formation of particular congener(s). The pattern, however, seems to change with burning materials and conditions, e.g., fuel to air ratio, furnace temperature, chlorine content and treatment method of waste gas. In fact, many different congener profiles have been reported for the waste gases of municipal incinerators. Hence, the congener profile appears to reflect the synthetic conditions of dioxins formation and is often called "fingerprint". However, the analysis of a congener profiles is practically difficult because it is a result of formation, accumulation and mixing of dioxins at different positions and time during the process.

The iron ore sintering is of course one of incineration processes, therefore its congener profile possesses the characteristics of an incineration pattern. Figure 5 shows examples of concentration profiles of previously reported toxic congeners, comparing to those measured at the entrances of D-EP of plants A and B in the present study. Common features can be pointed out for these profiles, e.g., the total concentration of PCDFs is larger than PCDDs by more than 10 times and concentrations of highly chlorinated congeners are larger in PCDDs.

Normalized congener profiles measured at several WBs of plant A are shown based on TEQ in Fig. 6. Although slight changes are seen in the profiles, 23478-P5CDF amounts 50 to $60 \%$ for all WBs.

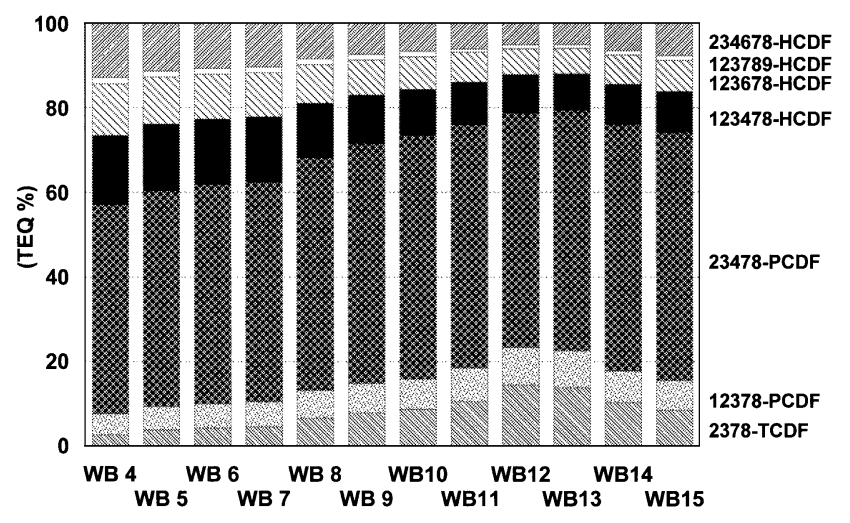

Fig. 6. Distribution of toxic congener profiles for exhaust gas from windboxes of plant A.

\subsection{Changes in PCDD/Fs Concentration during the Waste Gas Treatment}

Figure 7 shows the changes in the PCDD/Fs concentrations and their ratios of gas obtained from WBs to stack of plant A. The data for WBs is the value averaged by considering the concentration and gas flow rate of each WB. The concentration of $\mathrm{PCDD} / \mathrm{Fs}$ does not remarkably change from WBs $\left(195 \mathrm{ng} / \mathrm{Nm}^{3}\right)$ to the entrance of D-EP (190 $\left.\mathrm{ng} / \mathrm{Nm}^{3}\right)$ and then decreases down to a fairly small value, $17 \mathrm{ng} / \mathrm{Nm}^{3}$ (0.13 ng-TEQ/ $\left.\mathrm{Nm}^{3}\right)$, by the succeeding three gas treatment processes, i.e., D-EP, de-SOx and W-EP. This suggests that the formation of $\mathrm{PCDD} / \mathrm{Fs}$ is insignificant in WBs and gas duct to D-EP. A further decrease is also observed in de-NOx and finally gives the value of $7.3 \mathrm{ng} / \mathrm{Nm}^{3}$ $\left(0.04 \mathrm{ng}-\mathrm{TEQ} / \mathrm{Nm}^{3}\right)$. During the gas treatment processes, PCDFs holds a constant ratio, larger than $90 \%$. A discrepancy seen at de-NOx (out) seems to be an analytical error caused by the extremely low concentrations of PCDD/Fs. The decreases during the former three gas treatment processes are ascribable to the trap of PCDD/Fs stuck/adsorbed on dust particulates, while that during de-NOx process may be attributed to decomposition due by catalytic oxidation.

For Plant B, a little increase in PCDD/Fs concentration is found between WBs $\left(46 \mathrm{ng} / \mathrm{Nm}^{3}\right)$ and the entrance of D-EP $\left(58 \mathrm{ng} / \mathrm{Nm}^{3}\right)$. Then it decreases to $39 \mathrm{ng} / \mathrm{Nm}^{3}(0.63 \mathrm{ng}-$ $\mathrm{TEQ} / \mathrm{Nm}^{3}$ ) in D-EP.

\subsection{Material Flow of PCDD/Fs in the Sintering Process}

Table 3 shows PCDD/Fs concentration of solid materials, i.e., mill scale, blast furnace dust, D-EP dust, coke, granulated mixture of raw materials, returned fine sinter and produced sinter. D-EP dust gives comparably high concentration, $28 \mathrm{ng} / \mathrm{g}(0.73 \mathrm{ng}-\mathrm{TEQ} / \mathrm{g})$ and $52 \mathrm{ng} / \mathrm{g}(1.3 \mathrm{ng}-$ $\mathrm{TEQ} / \mathrm{g}$ ) for plant $\mathrm{A}$ and $\mathrm{B}$, respectively. The value for the produced sinter is fairly low. The returned fine sinter shows still a quite low value although it is larger than that of the produced sinter. It was confirmed that $\mathrm{PCDD} / \mathrm{Fs}$ concentration of the cooler gas of the produced sinter is as low as $0.95 \mathrm{ng} / \mathrm{Nm}^{3}\left(0.013 \mathrm{ng}-\mathrm{TEQ} / \mathrm{Nm}^{3}\right)$ for plant $\mathrm{A}$. This fact is well corresponding to the low value for the produced sinter.

A material flow of PCDD/Fs in plant $\mathrm{A}$ is drawn in Fig. 8. A certain amount of $\mathrm{PCDD} / \mathrm{Fs}$ originally contains in the raw mixture. It increases during sintering while the in- 
Table 3. $\mathrm{PCDD} / \mathrm{Fs}$ concentration of raw materials, recycled material and produced sinter.

\begin{tabular}{lllll}
\hline & Materials & PCDDs & $\begin{array}{c}\text { PCDFs } \\
(\mathrm{ng} / \mathrm{g})\end{array}$ & PCDD/Fs \\
\hline \multirow{4}{*}{ Plant A } & D-EP dust & 4.0 & 24 & 28 \\
& BF dust & 0.2 & 0.18 & 0.37 \\
& Mill scale & 0.064 & 0.084 & 0.15 \\
& Coke & 0.04 & 0.07 & 0.11 \\
& Returned ore & 0.027 & 0.016 & 0.043 \\
& Granulated mixture & 0.033 & 0.12 & 0.15 \\
& Produced sinter & 0.004 & 0.0008 & 0.005 \\
\hline \multirow{3}{*}{ Plant B } & D-EP dust & 6.0 & 46 & 52 \\
& Granulated mixture & 0.053 & 0.082 & 0.13 \\
\hline
\end{tabular}

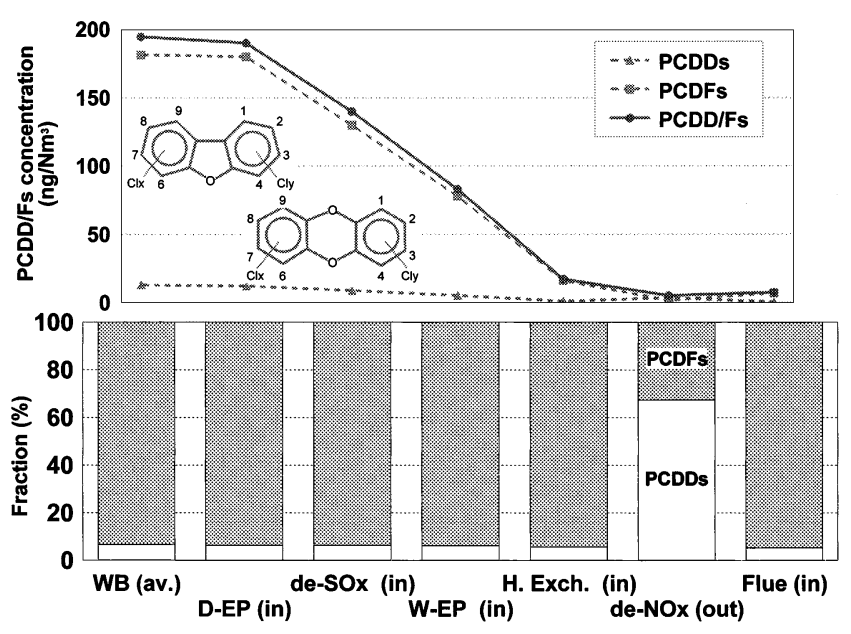

Fig. 7. Change in $\mathrm{PCDD} / \mathrm{Fs}$ concentration and their ratio during gas treatment.

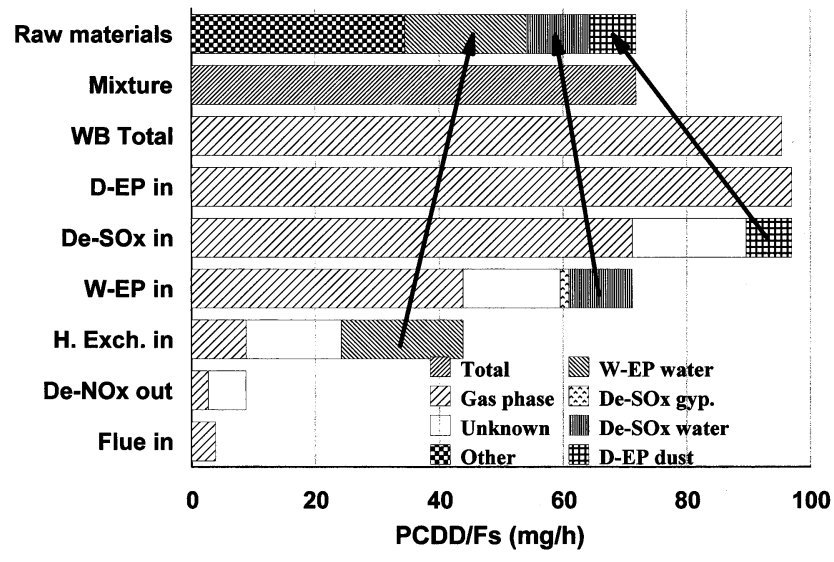

Fig. 8. Flow of $\mathrm{PCDD} / \mathrm{Fs}$ in sintering plant $\mathrm{A}$.

creased amount is relatively small, i.e., $25 \%$. The amount of PCDD/Fs does not change in the gas duct from WBs to the entrance of D-EP as similarly shown in Fig. 7. A part of trapped $\mathrm{PCDD} / \mathrm{Fs}$ in the gas treatment processes is recycled as the forms of dusts and water for granulation and the amount exhausted to the atmosphere is quite small. However, the term "Unknown" appeared in the figure indicates the parts missing their destination and their amounts cannot be disregarded. It may be resulted from errors in the analyses and/or the samplings. Most parts of the "Unknown" PCDD/Fs appear to be recycled into the raw

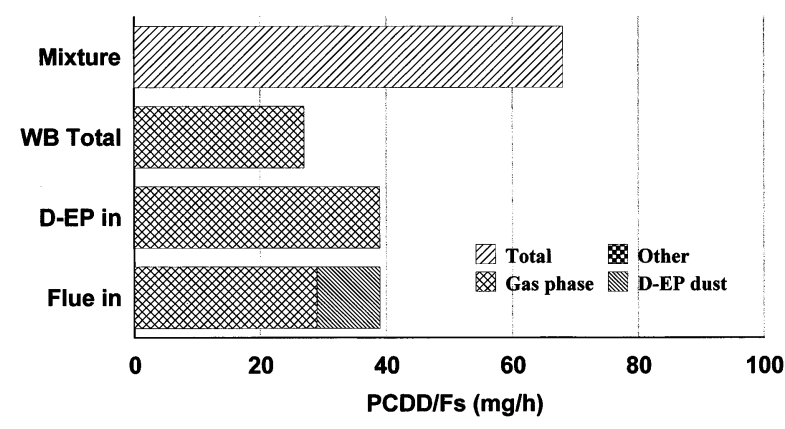

Fig. 9. Change in the amount of PCDD/Fs in sintering plant B.

mixture.

Recycle materials (dusts and water) admixed with raw materials are different between plants A and B because of the difference of applied gas treatment processes. However, the difference in PCDD/Fs concentrations of the mixture is not very large; 0.15 and $0.13 \mathrm{ng} / \mathrm{g}$-dry for plant $\mathrm{A}$ and $\mathrm{B}$, respectively. On the contrary, the change in the amount of $\mathrm{PCDD} /$ Fs during sintering is considerably dissimilar. For plant A, the amount of PCDD/Fs rather increases during sintering in the plant A as mentioned above. While the data obtained for plant B shows the significant decrease in the amount of PCDD/Fs during sintering (Fig. 9). This may support the possibility to decompose dioxins in the combustion bed of coke particles ${ }^{7)}$ like sintering process, although a further verification is necessary.

For plant $\mathrm{B}$, the amount of PCDD/Fs significantly increases from WBs to the entrance of D-EP. This may show their new formation in the gas duct and it does not agree with the results for plant $\mathrm{A}$. The large differences can be seen between the amount of PCDD/Fs collected as dust in D-EP and that of D-EP dust actually used as raw materials of plant B. This may be caused by the fluctuation of $\mathrm{PCDD} / \mathrm{Fs}$ concentration of D-EP dust in a certain term. In order to examine the flow of dioxins in detail, continuous and more systematic measurements are necessary.

\subsection{Co-PCBs}

Co-PCBs concentration in the gas was also occasionally analyzed. In terms of actual concentration, relatively larger values were observed for the congeners of IPAC (International Union of Pure and Applied Chemistry) No.

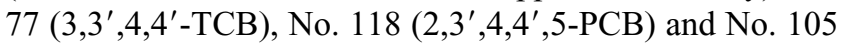
$\left(2,3,3^{\prime}, 4,4^{\prime}-\mathrm{PCB}\right)$. For toxicity, however, contribution of IPAC No. $126\left(3,3^{\prime}, 4,4^{\prime}, 5-\mathrm{PCB}\right)$ is remarkably large. Further, co-PCBs amounts to 5 to $10 \%$ of the total toxicity of dioxins.

\subsection{Plant Test on the Effect of Chlorine Content in Raw Materials on the Dioxin Emissions}

A test was carried out in plant B varying chlorine content in raw materials. The amount of input chlorine was changed by controlling the admixing ratios of dusts and mill scales, since their chlorine concentrations were relatively high. Figure 10 shows the relation between chlorine concentration of raw materials and PCDD/Fs concentrations at the entrance of D-EP. Both of the actual and toxicity concentrations of PCDD/Fs increase with increase in chlorine concentration. This strongly suggests that the chlorine in the raw materials affects dioxins emissions from sintering bed. 


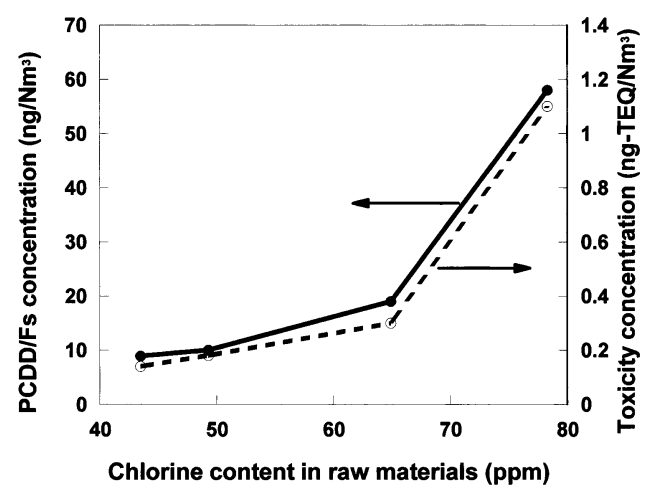

Fig. 10. Relation between chlorine content in the raw materials and PCDD/Fs concentration of gas at the entrance of DEP.

Concerning the congener profiles, however, no significant change is observed. It also appears that certain catalytic materials contained together with chlorides in the dusts and mill scale have some effect on the formation of dioxins.

\section{Discussions}

In waste incinerators and the treatment processes of their fly ashes, concentration ratio of PCDDs to PCDFs seems to be variable. In the sintering process, however, it shows a rather stable value and the fraction of PCDFs is considerably large as shown Fig. 7. One of the reasons may be attributed to a stable composition of raw materials. It is interesting that similar trends to the sintering process can be seen for the exhaust gases from the smelting processes of copper and zinc. ${ }^{8)}$ It is also noteworthy that higher ratios of PCDFs to PCDDs have reported during heat treatments of the mixture of carbon particles, e.g., soot and activated carbon, and copper or iron chlorides. The ratio of PCDFs to PCDDs is about 20 for iron chloride ${ }^{9)}$ and 10 for copper chloride. ${ }^{10)}$ These values are fairly comparable to that of the sintering process. Further, it was recently reported that the larger ratio of PCDFs to PCDDs was obtained at lower temperature during heat treatment of PVC and copper oxide powders in a sealed ampoule. ${ }^{11)}$ Hence, in order to search the formation mechanism of dioxins in the sintering process, it will be necessary to first consider de novo synthesis with catalysis of metal or metallic compound.

Generally, a major reaction of de novo synthesis seems to be regarded as partial oxidation of carbon particles having imperfect crystal structures of graphite. The reaction is promoted by the co-existing metals and metallic compounds, such as copper and iron. Certain chlorides of metal promote the reaction since it acts as both of source of chlorine and catalyst. Therefore, it may be deduced that a major root of dioxins formation in the sintering plant relates to carbon particles in own dusts. Taking into account of the suitable temperature for de novo synthesis, the potential positions where dioxins form are drying, calcinations and combustion zones in sintering bed, WBs at the later stage of sintering, duct from WBs to D-EP and inside of D-EP. However, the formation of dioxins at each position appears to be significantly influenced by the operational conditions of the sintering machine and incidental facilities.

The effect of raw materials on the dioxins formation dur- ing sintering has been examined systematically by using sinter-pots. The results will be also reported elsewhere. ${ }^{12)}$ Further, studies to search a principle for in situ suppression of dioxins formation in the sintering bed are continued by the project.

\section{Conclusions}

Macroscopic behavior of dioxins in the sintering process of iron ores were examined for different two sintering plants. Concentrations of PCDD/Fs as well as other gas species were determined for gases sampled at windboxes and the entrances and outlets of the gas treatment processes. Analysis of PCDD/Fs was also made for raw materials, dusts and water from the gas treatment processes and produced sinter. Further, a plant test was conducted with and without use of recycling materials. The results obtained are listed as follows:

(1) PCDD/Fs tend to be discharged in the later stage of sintering, similarly to SOx and $\mathrm{HCl}$.

(2) Within the PCDD/Fs homologues, the highly chlorinated homologues are discharged earlier than the lower ones. It is conflict with the fact that saturated vapor pressure of the PCDD/Fs generally decrease with an increase in the number of chlorination.

(3) Congener profiles observed for exhaust gases and EP dusts shows an incineration pattern, while concentration of PCDFs is larger than that of PCDDs by over 10 times.

(4) $\mathrm{PCDD} / \mathrm{Fs}$ possibly form in windboxes and an electrostatic precipitator as well as in the sintering bed. However, the net increase in the amount of PCDD/Fs is not necessarily large during the process. Moreover, the sintering bed may act as even a decomposition process of PCDD/Fs depending on the operational conditions, when the raw materials contain a certain level of PCDD/Fs.

(5) Most of PCDD/Fs discharged to the windboxes seems to correspond with those originally contained in the raw materials, since $\mathrm{PCDD} / \mathrm{Fs}$ recycled within the plants are comparably large. They are partially trapped in the succeeding gas treatment processes.

(6) Co-PCBs amounts 5 to $10 \%$ of the total toxicity of dioxins discharged from the sintering machine.

(7) The kinds and their admixing ratios of recycle materials, i.e., dusts and mill scale, affect the PCDD/Fs concentrations of exhaust gas from the sintering machine. The $\mathrm{PCDD} / \mathrm{Fs}$ concentrations are roughly related to the total chlorine content of the raw materials.

\section{Acknowledgements}

This study was financially supported by the Steel Industry Foundation for the Advancement of Environmental Protection Technology. The authors express their gratitude to other members of the Collaborative Research Project for Suppression of Dioxin Emissions from the Sintering Process (SDD Project) and for their earnest discussions and useful suggestions.
Abbreviation list
co-PCBs : Co-planar PolyChlorinated Biphenyls
D-EP : Dry Electrostatic Precipitator
PCDDs : polychlorinated dibenzo- $p$-dioxins
PCDFs : polychlorinated dibenzofurans 
PCDD/Fs : The sum of PCDDs and PCDFs

TEQ: Toxicity Equivalent Quantity (The sum of toxicities for all toxic congeners of dioxins expressed as the quantity of 2378-T4CDD, which is recognized as the most toxic congener.)

TDI : Tolerable Daily Intake (in pg-TEQ/kg-body)

WBs : WindBoxes

W-EP : Wet Electrostatic Precipitator

\section{REFERENCES}

1) G. Broker, P. Bruckmann and H. Gliwa: Organogen Compounds, 11 (1993), S.303.

2) "Method for determination of tetra- through octa-chlorodibenzo-pdioxins, tetra- through octa-chlorodibenzofurans and coplanar poly- chlorobiphenyls in stationary source emissions", JIS K 0311, (1999).

3) R. Putz and H. W. Gudenau: VDI-Brichte, (1996), No. 1298, 249.

4) B. F. Rordorf: Chemosphere, 18 (1989), 783.

5) USINOR, France: Private communication.

6) R. Fisher, T. A. T. Fray and D. R. Anderson: Ironmaking Conf. Proc., ISS, Warrendale, (1998), 1183.

7) E. Kasai, S. Harjanto, T. Terui, T. Nakamura and Y. Waseda: Chemosphere, 41 (2000), 857.

8) A. Buekens, E. Cornelis, H. Hiang and T. Dewettinck: Organohalogen Compounds, 36 (1998), 123.

9) S. P. Ryan and E. R. Altwicker: Organohalogen Compounds, 36 (1998), 269.

10) R. Addink and E. R. Altwicker: Organohalogen Compounds, 36 (1998), 73.

11) E. Shibata, S. Yamamoto, T. Nakamura and E. Kasai: Organohalogen Compounds, 46 (2000), 221.

12) E. Kasai, Y. Hosotani, T. Kawaguchi, K. Nushiro and T. Aono: ISIJ Int., 41 (2001), 93. 